\title{
CDISC Major Depressive Disorder Therapeutic Area User Guide Version 1.0
}

National Cancer Institute

\section{Source}

National Cancer Institute. CDISC Major Depressive Disorder Therapeutic Area User Guide Version 1.0. NCI Thesaurus. Code C161446.

The 1.0 version of the CDISC Major Depressive Disorder therapeutic area user guide. 